\title{
Compartilhamento de Conhecimento e Mentoring no Contexto da Indústria de Software
}

\author{
Marcelo Henrique Curbete ${ }^{1, *}$, Rejane Sartori ${ }^{1}$ \\ Hilka Pelizza Vier Machado ${ }^{1}$
}

\section{Resumo}

O mentoring é uma prática empregada para compartilhar conhecimento entre pessoas mais experientes e menos experientes, representando uma possibilidade de aprendizagem. Em empresas de base tecnológica o conhecimento e o capital humano ocupam uma posição estratégica. Nesse sentido, o objetivo desta pesquisa foi compreender a relação entre a adoção de práticas de mentoring e o compartilhamento de conhecimento em uma empresa de desenvolvimento de software. É um estudo qualitativo, com o emprego do método de estudo de caso. Os dados foram coletados por meio de questionários conduzidos junto aos envolvidos no Programa Mentor dessa empresa. Os resultados indicam que o mentoring exerceu influência no modo e na quantidade de conhecimento compartilhado entre profissionais, com implicações da relação mentor-mentorado tanto no desenvolvimento profissional como nos relacionamentos pessoais. No mentorado evidenciam-se tipos e formas de compartilhamento, como reuniões, pair programming, avaliações formais e informais e leitura, bem como habilidades adquiridas pelos participantes e respectivas vivências.

Palavras-chave: compartilhamento de conhecimentos, mentoring, empresas de software.

\section{Knowledge Sharing in Mentoring in the Context of the Software Industry}

\section{Compartir el Conocimiento en el Contexto de la Industria del Software}

\begin{abstract}
Sharing knowledge is essential in contemporary knowledge-driven organizations. Thus mentoring is a practice used to share knowledge among more and less experienced people. In this sense, this research aims to understand the relationship between the adoption of mentoring practices and the sharing of knowledge in a software development company. This is a qualitative study, using the case study method. Data was collected through questionnaires conducted with those involved in the Mentor Program of this company. The results indicate that mentoring influences the way and amount of knowledge shared among professionals, with implications of the mentor-mentor relationship in both professional development and personal relationships. Mentoring shows types and forms of sharing, such as meetings, pair programming, formal and informal assessments and reading, as well as skills acquired by participants and their experiences.
\end{abstract}

Keywords: knowledge sharing, mentoring, software company.

\section{Resumen}

El compartir el conocimiento es esencial en organizaciones contemporáneas orientadas al conocimiento, siendo el mentoring una práctica empleada para compartir conocimiento entre personas más experimentadas y menos experimentadas. En este sentido, el objetivo de esta investigación fue comprender la relación entre la adopción de prácticas de mentoring y el intercambio de conocimiento en una empresa de desarrollo de software. Es un estudio cualitativo, con el empleo del método de estudio de caso. Los datos fueron recolectados por medio de cuestionarios conducidos junto a los involucrados en el Programa Mentor de esa empresa. Los resultados indican que el mentoring ejerce influencia en el modo y la cantidad de conocimiento compartido entre profesionales, con implicaciones de la relación mentor-mentorado tanto en el desarrollo profesional como en las relaciones personales. En el mentor se evidencian tipos y formas de compartir, como reuniones, pair programming, evaluaciones formales e informales y lectura, así como habilidades adquiridas por los participantes y sus vivencias.

Palabras-clave: compartir conocimiento, tutoría, empresa de software.
* Informações sobre o autor principal:

Avenida Fagundes Filho, 623 - Apto. 166 Esparta - São Paulo - SP

E-mail: marcelo.curbete@gmail.com
Como citar esse artigo: Curbete, M. H., Sartori, R., \& Machado, H. P. V. (2020). Compartilhamento de Conhecimento e Mentoring no Contexto da Indústria de Software. Revista Psicologia: Organizações e Trabalho, 20(2), 984-993. https://doi.org/10.17652/rpot/2020.2.17676 
A troca de conhecimentos e de experiências entre pessoas nas organizações é importante tanto para promover a integração entre os indivíduos como também para propiciar a melhoria dos serviços ofertados. Para que as organizações obtenham ganhos, elas precisam ser capazes de transformar seu conhecimento em produtos e serviços rentáveis (Agarwal \& Islam, 2015). Nesse sentido, é interessante que a troca de conhecimentos ocorra de modo contínuo, cíclico e ilimitado. A externalização e a socialização de conhecimentos em organizações permitem, como considera Dalkir (2011), que os relacionamentos se consolidem e tenham visibilidade, o que contribui para evidenciar como o conhecimento flui, de quem se origina e para quem será transmitido.

Para Anand e Walsh (2016), o compartilhamento do conhecimento propicia o compartilhamento de saberes e aprimoramento de experiências, favorecendo a tomada de decisões e a melhoria do relacionamento com clientes e com a cadeia produtiva, além de possibilitar a redução de custos intermediários e finais no negócio (Smite, Moe, Sablis, \& Wohlin, 2017). Assim, o compartilhamento do conhecimento pode resultar em melhoria de produtividade nas organizações (Dalkir, 2011).

Uma das práticas de compartilhamento do conhecimento é o mentoring. Em linhas gerais, o mentoring é um processo em que se estabelece uma relação entre uma pessoa mais experiente (mentor) com outra menos experiente (mentorado), com o objetivo de orientar o crescimento pessoal e profissional desse último ( $\mathrm{K}$. F. F. Silva, 2008). Nesta pesquisa, o mentoring é considerado uma prática de desenvolvimento profissional, pautada no apoio de um indivíduo especialista ou mais experiente junto a outro menos experiente, com o objetivo de melhorar seu desempenho e a inserção na organização. Para Oliveira Neto e Souza-Silva (2017, p. 64), “a mentoria é um fenômeno associado aos processos de aprendizagem organizacional, sendo mais especificamente uma modalidade da abordagem sócio prática de aprendizagem organizacional”.

Especialmente em empresas de base tecnológica, o conhecimento e o capital humano ocupam uma posição estratégica. Entre essas empresas encontram-se as do setor de Tecnologia da Informação (TI), que apresentam atualmente crescimento constante em todo mundo e que são intensivas em conhecimento. Essas empresas buscam desenvolver seus profissionais de maneira a agregar maior conhecimento sobre ferramentas de desenvolvimento de sistemas, linguagens de programação, conhecimento do negócio e instruções sobre o uso de programas a serem desenvolvidos (Smite et al., 2017; Moreno, Cavazotte, \& Arruda, 2014).

Considerando a relevância destas empresas e a importância do compartilhamento do conhecimento em empresas de tecnologia, esta pesquisa teve como objetivo compreender a relação entre a adoção de práticas de mentoring e o processo de compartilhamento do conhecimento, tendo com objeto de pesquisa uma empresa de desenvolvimento de software. Neste artigo será inicialmente apresentada uma breve revisão da literatura sobre compartilhamento do conhecimento e mentoring e, em seguida, são descritos os procedimentos metodológicos da pesquisa e a apresentação e análise dos resultados obtidos junto aos participantes da pesquisa.

\section{Compartilhamento do Conhecimento e Mentoring}

O compartilhamento do conhecimento é um tema relativamente recente, uma vez que as publicações a seu respeito começaram a acontecer de forma expressiva a partir de 2009, e diz respeito à transmissão de conhecimentos e experiências entre indivíduos, oferecendo a possibilidade de ampliar conhecimentos (Osinski, Roman, \& Selig, 2015).

$\mathrm{Na}$ Tabela 1 encontram-se sistematizados alguns conceitos sobre compartilhamento de conhecimento. Contu- do, independente do autor, todas as definições convergem no sentido de que o compartilhamento auxilia na ampliação e difusão de ideias, experiências, informações e conhecimento.

Tabela 1

Conceitos de compartilhamento do conhecimento

\begin{tabular}{|c|c|}
\hline Autor & Conceito \\
\hline $\begin{array}{l}\text { Van den Hooff e Van } \\
\text { Weenen (2004) }\end{array}$ & $\begin{array}{l}\text { Processo que resulta tanto em doar conhecimento } \\
\text { como em recebê-lo, possibilitando ao indivíduo }\end{array}$ \\
\hline $\begin{array}{c}\text { Brachos, Kostopoulos, } \\
\text { Soderquist e Prastacos } \\
\text { (2007) }\end{array}$ & $\begin{array}{c}\text { combinar ideias, opiniões e informações distintas } \\
\text { e oportunizando construir novos conhecimentos a } \\
\text { partir daqueles adquiridos por outros. }\end{array}$ \\
\hline Tonet e Paz (2006) & $\begin{array}{l}\text { Processo que envolve a percepção de compreender } \\
\text { os acontecimentos que se sucedem a partir do mo- } \\
\text { mento em que as pessoas compartilham informa- } \\
\text { ções em um contexto de trabalho. Inclui troca de } \\
\text { experiências e conhecimentos. }\end{array}$ \\
\hline Yang (2007) & $\begin{array}{l}\text { Conjunto de comportamentos que envolvem o } \\
\text { intercâmbio de conhecimentos sobre os atores, co- } \\
\text { nhecimento do conteúdo, contexto organizacional, } \\
\text { meios adequados e ambientes sociais. }\end{array}$ \\
\hline Reis (2016) & $\begin{array}{l}\text { Cadeia de eventos, a partir da identificação do co- } \\
\text { nhecimento chave necessário e das pessoas que ne- } \\
\text { cessitam desse conhecimento. Ocorre na interação } \\
\text { pessoal, no relacionamento social, seja em nível de } \\
\text { conhecimento tácito ou de conhecimento explícito. }\end{array}$ \\
\hline $\begin{array}{c}\text { Gonzalez e Martins } \\
\text { (2017) }\end{array}$ & $\begin{array}{c}\text { Troca de experiências e conhecimento entre } \\
\text { indivíduos via contato social, em uma perspectiva } \\
\text { de compartilhamento do conhecimento tácito e } \\
\text { explícito. }\end{array}$ \\
\hline
\end{tabular}

Nota. Fonte: Elaborado pelos autores.

Massingham (2014) defende que compartilhar conhecimentos sobre melhores práticas e procedimentos, definindo padrões operacionais de armazenamento de dados e recuperação de informações que enfatizem formas de promover, motivar, incentivar, fomentar e guiar o processo do conhecimento contribui para a captura e distribuição do conhecimento.

O compartilhamento de conhecimento equivale ao ato de compartilhar experiências pessoais relacionadas ao trabalho de forma voluntária com outros indivíduos, grupos e parceiros na organização (Kim \& Lee, 2006) e, nesse sentido, ele não pode ser forçado, mas pode ser encorajado pelas políticas organizacionais e facilitado pela estrutura organizacional (Kuo, 2013).

Com o objetivo de entender o que acontece quando indivíduos compartilham conhecimentos, bem como para analisar os elementos que integram esse processo, Tonet e Paz (2006) desenvolveram um modelo para compartilhamento de conhecimento que, segundo as autoras, tem como foco principal o processo que ocorre em grupos de trabalho, sendo a organização considerada como elemento do contexto em que esses grupos estão inseridos. Esse modelo está ancorado na Teoria de Sistemas (Bertalanffy, 1975) e em teorias da comunicação humana (Berlo, 1970; Thayer, 1979; Thompson, 1973). Além disso, as autoras afirmam que o processo de compartilhamento do conhecimento se desdobra em quatro fases: iniciação, implementação, apoio e incorporação, as quais se desenvolvem por meio da articulação de quatro elementos: a fonte do conhecimento a ser compartilhado, o destinatário desse conhecimento, o conhecimento em si e o contexto em que o compartilhamento do conhecimento ocorre.

A primeira fase, iniciação, consiste em ações orientadas à identificação e análise de necessidades de conhecimentos a serem compartilhados. Nesta fase também é verificada a existência de oportunidades para a utilização de novos conhecimentos, além da identificação das fontes a partir das quais estes conhecimentos podem ser obtidos. A segunda fase, implementação, se refere ao desempenho de ações voltadas para integrar fontes e alvos do conhecimento. Nesta fase devem ser estabele- 
cidos vínculos entre a fonte do conhecimento demandado e seu destinatário; também são definidas as condições para que a troca de conhecimento ocorra de forma eficiente, com identificação do contexto. A terceira fase, apoio, tem o objetivo de criar oportunidades para esclarecer e retificar conhecimentos já transmitidos e assim evitar o uso indevido e inadequado do conhecimento ou o retorno à fase anterior. Por fim, a fase da incorporação é responsável pela disseminação do conhecimento compartilhado e envolve a aplicação prática do conhecimento recebido.

Reforçando essas explicações de Tonet e Paz (2006), Binotto, Nakayama e Siqueira (2013) afirmam que o compartilhamento de conhecimento acontece do nível individual para o coletivo, organizacional, como também entre organizações. Além disso, Rodriguez, Muniz e Munyon (2018) corroboram com a perspectiva do indivíduo quando afirmam que a atitude é um fator que influencia a intenção de compartilhamento de conhecimento.

Tonet e Paz (2006) observam ainda que o conhecimento precisa apresentar três características principais: 1) compreensibilidade, refletida na facilidade de absorção do conhecimento; 2) utilidade para aquele que agregará o conhecimento à sua vivência e 3) validade. As duas últimas relacionam-se ao modo de aplicar o conhecimento e ao percentual de atendimento que o compartilhamento trará à prática do indivíduo. A primeira está diretamente ligada ao compartilhamento do conhecimento e diz respeito ao modo de realização desse processo, pois quanto mais o receptor compreende o conhecimento compartilhado, menor ambiguidade haverá no resultado desse compartilhamento.

No caso de empresas de software, Moreno et al. (2014) constataram que nessas empresas o compartilhamento do conhecimento influencia $\mathrm{o}$ alinhamento operacional entre as áreas. Como essas empresas trabalham com projetos colaborativos, elas integram informação e conhecimento e o compartilhamento de conhecimento contribui para aumentar a capacidade de absorção, que, por sua vez, necessita ser constantemente renovada nesse campo (Ayres \& Popadiuk, 2016). Acrescentam Miguel e Popadiuk (2019) que o compartilhamento é um processo de interação simbólica, mediado pela semiótica.

Dadas tais condições, o mentoring é considerado uma forma de compartilhamento do conhecimento e pode ser entendido em diferentes contextos e situações, com peculiaridades entre mentor e mentorado. $\mathrm{Na}$ Tabela 2 são apresentados alguns conceitos de mentoring de acordo com a visão de alguns autores que tratam dessa temática.

É possível identificar que o foco principal dessas definições se encontra na relação que se estabelece entre duas pessoas, sendo que uma pessoa detém grau maior de experiência sobre um assunto específico ou processo de trabalho. Esta pessoa - o mentor - se propõe a compartilhar seu conhecimento com outros menos experientes e que necessitam de orientação para o desenvolvimento profissional - os mentorados. Assim, o mentoring ocorre quando há colaboração de um mentor ao ensinar um mentorado a executar determinada tarefa ou processo. Para C. R. E. Silva (2010, p. 302) o mentor pode ser entendido como "alguém especializado em determinada área de atuação, o qual busca repassar seus conhecimentos e experiência a outros menos experientes". Segundo o autor, o que distingue o mentor do coach é que este último não precisa ser especialista na área.

De acordo com Kram (1988), o mentoring é uma prática que passa por quatro fases distintas: iniciação, cultivação, separação e redefinição. Além disso, segundo a autora, possui funções com características específicas que visam melhorar o crescimento e o desempenho do mentorado junto à empresa. Na visão da autora, essas funções se dividem entre carreira e psicossocial, as quais consistem em aspectos da relação entre mentores e mentorados
Tabela 2

Conceitos de mentoring

\begin{tabular}{|c|c|}
\hline Autor & Conceito \\
\hline $\begin{array}{l}\text { Kram } \\
(1988)\end{array}$ & $\begin{array}{l}\text { Relação de alguém com mais experiência e conhecimento na } \\
\text { área de atuação do novo contratado e que passa seu legado a ele, } \\
\text { dando suporte técnico e efetivo, não lhe cabendo um papel de } \\
\text { promotor desse empregado no alcance de cargos ou indicações } \\
\text { de promoção. }\end{array}$ \\
\hline $\begin{array}{l}\text { Bellodi e } \\
\text { Martins } \\
(2005)\end{array}$ & $\begin{array}{l}\text { Modalidade especial de relação de ajuda em que, essencialmente, } \\
\text { uma pessoa mais experiente acompanha de perto, orienta e es- } \\
\text { timula - a partir de sua experiência, conhecimento e comporta- } \\
\text { mento - um jovem iniciante em sua jornada no desenvolvimento } \\
\text { de sua vida pessoal e profissional. }\end{array}$ \\
\hline $\begin{array}{c}\text { K. F. F. } \\
\text { Silva (2008) }\end{array}$ & $\begin{array}{l}\text { Processo em que se estabelece uma relação entre uma pessoa } \\
\text { mais experiente - mentor - com uma outra com menos } \\
\text { experiência - mentorado - com o objetivo de orientar para o } \\
\text { crescimento pessoal e profissional. }\end{array}$ \\
\hline
\end{tabular}

Zachary Configura-se quando há uma relação de trabalho entre membros (2011) sênior e júnior dentro da organização.

\begin{tabular}{|c|c|}
\hline $\begin{array}{c}\text { Almeida e } \\
\text { Souza-Silva } \\
(2015)\end{array}$ & Modalidade de aprendizagem organizacional. \\
\hline $\begin{array}{l}\text { Oliveira } \\
\text { Neto e } \\
\text { Souza-Silva } \\
\text { (2017) }\end{array}$ & $\begin{array}{l}\text { No campo organizacional, a mentoria representa um relaciona- } \\
\text { mento entre um profissional mais experiente (mentor) e outro } \\
\text { menos experiente (discípulo, mentorado, protégé) com o propó- } \\
\text { sito de fomentar, sobretudo, o desenvolvimento deste último na } \\
\text { prática laboral. }\end{array}$ \\
\hline
\end{tabular}

Nota. Fonte: Elaborado pelos autores.

que visam a fortalecer o crescimento e o desenvolvimento de ambos, seja no âmbito pessoal ou profissional. Kram (1988) afirma que são consideradas funções de carreira o patrocínio, a exposição e visibilidade, o coaching, a proteção e as tarefas desafiadoras. As funções psicossociais abarcam a criação de um elo de confiança e intimidade entre mentor e mentorado, sendo que esse apoio emocional pode ser essencial no desenvolvimento da carreira do mentorado. Enquanto as funções de carreira dependem da posição e influência da pessoa sênior na organização, as funções psicossociais dependem mais da qualidade da relação interpessoal. Ainda de acordo com a autora, são funções psicossociais a modelagem de papeis, aceitação e confirmação, aconselhamento e amizade. Além disso, Oliveira Neto e Souza-Silva (2017) salientam que a mentoria, enquanto modalidade de aprendizagem organizacional, é influenciada pela cultura organizacional, na medida em que, para a abordagem sócio-prática, o conhecimento é prático e relacional.

Diversos são os benefícios que a prática do mentoring pode propiciar nos distintos segmentos organizacionais. Pesquisa realizada por Santos (2015) identificou algumas vantagens da aplicação dessa prática tanto para as organizações quanto para o capital humano, a saber: a) A cultura corporativa é positivamente afetada, pois a prática do mentoring permite a disseminação das crenças e valores organizacionais.

b) A prática do mentoring apoia substancialmente a retenção de talentos, visto que mentores podem ser reconhecidos como referencial de atuação e mentorados vislumbram a oportunidade que a empresa lhes concede para o desenvolvimento de carreira, oferecendo o suporte que precisam.

c) Por meio de seu processo sistêmico, o mentoring preserva o conhecimento organizacional, permitindo à organização a manutenção e perenidade dos seus saberes.

d) Na ótica da meritocracia, a prática do mentoring possibilita identificar a contribuição dos colaboradores, propiciando a valorização da colaboração individual e em equipe.

e) Por meio do desenvolvimento de conhecimentos, habilidades e atitudes, o progresso do capital huma- 
no potencializa a geração de resultados para a organização. f) Por ser uma prática de relacionamento humano e interpessoal, o mentoring promove a integração das pessoas da organização.

As fases e ações que compõem a prática do mentoring, como apontado por Kram (1998), são, de certa forma, alinhadas às fases e ações do processo de compartilhamento de conhecimento de Tonet e Paz (2006), como pode ser observado na Tabela 3. Essa similaridade é um fato esperado, uma vez que a aplicabilidade do mentoring no processo de compartilhamento de conhecimento foi anteriormente demonstrada no Manual de Práticas e Técnicas de Gestão do Conhecimento da Asian Productivity Organization (Young, 2010). Convém salientar que o compartilhamento pode ser produzido em outros espaços, como comunidades de prática, repositórios de conhecimento, banco de competências, entre outros (Souza, Vasconcelos, Judice, \& Jamil, 2010).

Tabela 3

Fases e ações do processo de compartilhamento de conbecimento e da prática do mentoring

\begin{tabular}{cc}
\hline & Compartilhamento de conhecimento \\
\hline Fase & Ação \\
\hline Iniciação & $\begin{array}{c}\text { Identificação e análise de necessidades de conhecimento. } \\
\text { Identificação de oportunidades para emprego de novos } \\
\text { conhecimentos. } \\
\text { Identificação de fontes de conhecimento. }\end{array}$ \\
\hline
\end{tabular}

Implementação

Integração de fontes e destinatários do conhecimento.

\begin{tabular}{cc}
\hline & Espaços para compartilhar conhecimento. \\
Exercitar o conhecimento compartilhado. \\
Apoio \\
Comprovar a assimilação do conhecimento por meio do \\
desenvolvimento de habilidades.
\end{tabular}

Incorporação Disseminação e aplicação do conhecimento compartilhado. modo o mentoring influencia no compartilhamento de conhecimento de profissionais do setor de desenvolvimento de software?

O método escolhido foi o estudo de caso. O estudo de caso único procura explorar um fenômeno sob circunstâncias particulares, sendo que o pesquisador não tem controle sobre os eventos investigados (Yin, 2005). O estudo de caso foi desenvolvido junto aos atores do Programa Mentor de uma empresa da área de desenvolvimento de software. A empresa foi escolhida por ter implementado o Programa a um ano, tempo julgado necessário para a geração de resultados para a pesquisa.

\section{Participantes}

Participaram da pesquisa os atores do Programa Mentor de uma das unidades dessa empresa, composto pelo gerente de Re-

\begin{tabular}{cc} 
& \multicolumn{2}{c}{ Mentoring } \\
\hline Fase & \multicolumn{1}{c}{ Ação } \\
\multirow{3}{*}{ Iniciação } & Os pares são atraídos para interação: \\
& -Seleção dos mentores e mentorados. \\
& -Identificação das expectativas do mentorado. \\
& -Estabelecimento de metas a serem atingidas. \\
\hline
\end{tabular}

Fase ativa de mentoring:

-Mentor prepara os mentorados quanto aos conhecimentos técnicos e perfis comportamentais; alinha as expectativas da empresa junto ao mentorado; aproxima-se do mentorado. -Mentorado deve analisar as situações que presenciou na empresa; aprender lições e colher benefícios do programa. Separação $\quad$ Ruptura do relacionamento entre mentor e mentorado.
Avaliação dos mentorados.

\begin{tabular}{|c|c|}
\hline Redefinição & $\begin{array}{l}\text { Restabelecimento do relacionamento entre mentor e men- } \\
\text { torado. } \\
\text { Fortalecimento dos laços entre mentor e mentorado. } \\
\text { Reconhecimento das capacidades do mentor e mentorado. }\end{array}$ \\
\hline
\end{tabular}

Nota. Fonte: Elaborado pelos autores com base em Kram (1998) e Tonet e Paz (2006).

\section{Método}

Esta pesquisa procurou compreender a relação entre a adoção de práticas de mentoring e o compartilhamento de conhecimento em uma empresa de desenvolvimento de software. Para tanto, foi realizada uma pesquisa qualitativa e exploratória. Para Cooper e Schindler (2003), o estudo exploratório contribui para aumentar o entendimento sobre determinado problema de pesquisa, além de reunir informações para refinar questões em torno do referido problema.

Este estudo qualitativo procurou responder à questão: de que cursos Humanos, quatro mentores e dez mentorados, totalizando 15 sujeitos da pesquisa. O questionário foi aplicado em outubro de 2017.

\section{Instrumento}

O instrumento utilizado para a coleta de dados foi um questionário, construído a partir de identificação, na literatura científi$\mathrm{ca}$, dos elementos presentes no mentoring que contribuem para o compartilhamento de conhecimento. Inicialmente foram identifi-

Tabela 4

Fases de análise do compartilhamento do conbecimento

\begin{tabular}{|c|c|c|}
\hline Fase & Ação & Elementos de Análise \\
\hline Iniciação & Necessidades e fontes de conhecimento & $\begin{array}{l}\text { Seleção das pessoas aptas a repassar o conhecimento necessário à empresa, ou seja, mentor. } \\
\text { Seleção de pessoas desejáveis para receber o conhecimento, ou seja, mentorados. } \\
\text { Identificação das expectativas do mentorado.Estabelecimento de metas a serem atingidas. }\end{array}$ \\
\hline Implementação & $\begin{array}{l}\text { Integração de fontes e destinatários do conheci- } \\
\text { mento }\end{array}$ & $\begin{array}{l}\text { Compartilhamento de conhecimento técnico e comportamental com o mentorado. } \\
\text { Recebimento de conhecimento técnico e comportamental pelo mentorado. } \\
\text { Análise das situações presenciadas na empresa. } \\
\text { Alinhamento das expectativas da empresa junto ao mentorado. } \\
\text { Aproximação do mentor junto ao mentorado. }\end{array}$ \\
\hline Apoio & $\begin{array}{l}\text { Comprovação, assimilação e exercício do conhe- } \\
\text { cimento }\end{array}$ & $\begin{array}{l}\text { Descontinuidade do relacionamento entre mentor e mentorado. } \\
\text { Utilização do conhecimento recebido no cotidiano. } \\
\text { Avaliação dos mentorados quanto à assimilação e utilização do conhecimento recebido. }\end{array}$ \\
\hline Incorporação & Disseminação do conhecimento compartilhado & $\begin{array}{l}\text { Retomada do relacionamento entre mentor e mentorado para adaptação a um novo trabalho. } \\
\text { Fortalecimento do relacionamento entre mentor e mentorado. } \\
\text { Reconhecimento das capacidades do mentor e mentorado. }\end{array}$ \\
\hline
\end{tabular}


cados, em cada fase e ação do processo de compartilhamento do conhecimento proposto por Tonet e Paz (2006), os atributos e ações presentes na prática do mentoring que contribuem para que o compartilhamento de conhecimento ocorra, os quais foram então descritos para expressar os elementos de análise do compartilhamento de conhecimento em uma organização, conforme mostrado na Tabela 4.

A partir da identificação desses elementos de análise, foi elaborado um questionário (Tabela 5) composto por 51 perguntas, com opções de respostas em diferentes formatos: aberta, dicotômica (sim/não), múltipla escolha e escala Likert em cinco níveis (1 a 5). O questionário foi dividido em três blocos: o primeiro direcionado ao Departamento de Recursos Humanos, o segundo orientado aos mentores e o terceiro dirigido aos mentorados.

\section{Procedimentos de Coleta de Dados e Cuidados Éticos}

Foi realizado um pré-teste da pesquisa com um mentorado e um mentor, a fim de verificar a compreensão do instrumen-

Tabela 5

Questionário da pesquisa to. Com a validação do instrumento, a pesquisa foi então efetuada em uma empresa atuante no setor de desenvolvimento de software, que tem sede em São Paulo e unidades em uma cidade do Estado de Santa Catarina e em outras duas do Estado do Paraná.

\section{Procedimentos de Análise dos Dados}

Após a aplicação do questionário os resultados qualitativos foram transcritos para uma planilha do Microsoft Excel, o que permitiu melhor visualização dos dados obtidos. A partir de então a categoria de análise foi composta pelas fases do compartilhamento de conhecimento de Tonet e Paz (2006), iniciação, implementação, apoio e incorporação (Tabela 3).

\section{Resultados e Discussão}

A organização objeto deste estudo é uma empresa que oferece soluções em software, serviços e gestão de processos administrativos, auxiliando a gestão corporativa dos seus clientes.

\begin{tabular}{|c|c|c|}
\hline \multicolumn{3}{|c|}{ BLOCO 1 - RECURSOS HUMANOS } \\
\hline & Programa Mentor & Tipo de resposta \\
\hline 1. & A empresa disponibiliza espaço e tempo (de mentores e mentorados) para compartilhamento de conhecimento? & Sim/Não \\
\hline 2. & De que forma são identificadas as necessidades de novos conhecimentos na empresa? & Aberta \\
\hline 3. & $\begin{array}{l}\text { Considerando a necessidade de conhecimento identificada pela empresa, como são selecionados os mentores do Programa Mentor? E os } \\
\text { mentorados? }\end{array}$ & Aberta \\
\hline 4. & Como são identificadas as expectativas do mentorado em relação ao Programa? & Aberta \\
\hline 5. & São estabelecidas metas a serem atingidas? Em caso afirmativo, como são definidas e quem estabelece? & Aberta \\
\hline 6. & $\begin{array}{l}\text { Após o término do processo de compartilhamento do conhecimento, a empresa avalia o mentorado em relação à assimilação do conhe- } \\
\text { cimento recebido e ao desenvolvimento de habilidades? Como isso ocorre? Quais critérios são utilizados? }\end{array}$ & Aberta \\
\hline 7. & $\begin{array}{l}\text { Após o término do processo de compartilhamento do conhecimento, o mentor é avaliado? Como isso ocorre? Quais critérios são } \\
\text { utilizados? }\end{array}$ & Aberta \\
\hline 8. & A empresa toma medidas para fortalecer os laços entre mentor e mentorado após o término do Programa Mentor? & Aberta \\
\hline 9 . & Existe na empresa um sistema de reconhecimento e recompensas para mentores e mentorados? Em caso afirmativo, como isso ocorre? & Aberta \\
\hline
\end{tabular}

9. Existe na empresa um sistema de reconhecimento e recompensas para mentores e mentorados? Em caso afirmativo, como isso ocorre?

Aberta BLOCO 2 - MENTORES

\begin{tabular}{|c|c|c|}
\hline & Programa Mentor & Tipo de respost \\
\hline 1. & Qual foi o tempo que você participou do Programa Mentor? & Múltipla \\
\hline 2. & Que tipo de motivação o leva a atuar como mentor? & Aberta \\
\hline 3. & $\begin{array}{l}\text { Em média, seu mentorado se expressa/comunica facilmente? Ele tem habilidade para ouvir e refletir sobre o conhecimento recebido? } \\
\text { Ele tem habilidade de elaborar perguntas para esclarecer informações recebidas e direcionar sua aplicabilidade? }\end{array}$ & Likert (1-5) \\
\hline 4. & Com que frequência/tempo seu mentorado é capaz de aprender e usar o novo conhecimento? & Likert (1-5) \\
\hline 5. & Você compartilha os valores e crenças da empresa com seu mentorado? & $\operatorname{Sim} / \mathrm{Não}$ \\
\hline 6. & A empresa disponibiliza espaços e tempo (mentores e mentorados) para compartilhar conhecimento? & $\operatorname{Sim} / \mathrm{Não}$ \\
\hline 7. & De que forma são identificadas as necessidades de novos conhecimentos na empresa? & Aberta \\
\hline 8. & Você seleciona seu corpo de mentorados? Em caso afirmativo, como isso é feito? & Aberta \\
\hline 9. & As expectativas do mentorado são identificadas e consideradas no início do Programa Mentor? & Likert (1-5) \\
\hline 10. & Que tipo de conhecimentos você compartilha com seu mentorado? & Aberta \\
\hline 11. & De que maneira você compartilha os conhecimentos com seu mentorado? Quais são os procedimentos utilizados? & Aberta \\
\hline 12. & Durante Programa Mentor, você se aproximou mais de seu mentorado? Em caso afirmativo, de que forma isso ocorreu? & Aberta \\
\hline 13. & Em seu ponto de vista, quais são os aspectos positivos que a aproximação mentor-mentorado traz para o mentorado e para a empresa? & Aberta \\
\hline 14. & $\begin{array}{l}\text { Após a transmissão dos conhecimentos necessários e o término do Programa Mentor, ocorre descontinuidade do relacionamento entre } \\
\text { mentor e mentorado? }\end{array}$ & $\mathrm{Sim} / \mathrm{Não}$ \\
\hline 15. & Após o término do processo, você acredita que seu mentorado assimilouos conhecimentos necessários? & Aberta \\
\hline 16. & $\begin{array}{l}\text { Após o término do processo, você avalia o desempenho de seu mentorado em relação ao conhecimento que ele adquiriu? Como isso } \\
\text { ocorre? }\end{array}$ & Aberta \\
\hline 17. & Descreva quais foram as principais mudanças que você observou em seu mentorado após o Programa Mentor. & Aberta \\
\hline 18. & Você auxilia seu mentorado na sua adaptação em um novo cargo ou equipe, caso isto ocorra, após o término do Programa Mentor? & Sim/Não \\
\hline 19. & A empresa toma medidas para fortalecer os laços entre mentor e mentorado? Como isso ocorre? & Aberta \\
\hline 20. & De que forma a empresa efetua o reconhecimento das capacidades do mentor e mentorado? & Aberta \\
\hline 21. & Quais benefícios o Programa Mentor lhe proporcionou? & Aberta \\
\hline
\end{tabular}




\begin{tabular}{|c|c|c|}
\hline \multicolumn{2}{|r|}{ Mentor } & \multirow{2}{*}{$\frac{\text { Tipo de resposta }}{\text { Múltipla }}$} \\
\hline 1. & Seu mentor tem boa técnica comunicativa, prestígio na organização, qualificação e domínio do conhecimento? & \\
\hline 2. & Você acredita que seu mentor é competente em relação às funções que desempenha na empresa? & Aberta \\
\hline 3. & Você tem liberdade para reportar-se ao seu mentor quando necessário? & Likert (1-5) \\
\hline 4. & Você sabe ouvir e refletir sobre o conhecimento recebido? & Likert (1-5) \\
\hline 5. & Você elabora perguntas para esclarecer informações recebidas e direcionar sua aplicabilidade? & Sim/Não \\
\hline 6. & Com que frequência/tempo você consegue aprender e usar o novo conhecimento? & $\mathrm{Sim} / \mathrm{Não}$ \\
\hline 7. & Seu mentor compartilha com você os valores e crenças da empresa? & Aberta \\
\hline 8. & Quais foram as necessidades e expectativas que o levaram a querer participar do Programa Mentor? & Aberta \\
\hline 9. & Que tipo de conhecimentos seu mentor compartilha com você? & Likert (1-5) \\
\hline 10. & De que maneira seu mentor compartilha conhecimentos com você? Quais procedimentos utilizados? & Aberta \\
\hline 11. & Seu mentor expõe as expectativas dele e da empresa em relação à atividade de mentoria? Como isso ocorre? & Aberta \\
\hline 12. & Durante sua participação no Programa Mentor, você se aproximou mais do seu mentor? & Aberta \\
\hline 13. & Em seu ponto de vista, quais os aspectos positivos que a aproximação mentor-mentorado traz para você e para a empresa? & Aberta \\
\hline 14. & Quais situações você vivenciou na empresa e considera importantes para seu crescimento? & $\mathrm{Sim} / \mathrm{Não}$ \\
\hline 15. & Como você utiliza os conhecimentos obtidos durante sua participação no Programa Mentor na execução de suas atividades na empresa? & Aberta \\
\hline 16. & Após o processo de compartilhamento do conhecimento, quais novas habilidades você adquiriu? & Aberta \\
\hline 17. & Após sua participação no Programa Mentor, você compartilhou os conhecimentos recebidos com outros colegas? & Aberta \\
\hline 18. & Após o término do Programa Mentor, você conta com o auxílio do mentor? Como a empresa atua nesse processo? & $\mathrm{Sim} / \mathrm{Não}$ \\
\hline 19. & A empresa toma medidas para fortalecer os laços entre mentor e mentorado após o término do Programa Mentor? & Aberta \\
\hline 20. & Que medidas são tomadas pela empresa para reconhecer as capacidades do mentorado? & Aberta \\
\hline 21. & Quais benefícios o Programa Mentor lhe proporcionou? & Aberta \\
\hline
\end{tabular}

Nota. Fonte: Elaborado pelos autores.

Atua em segmentos como logística, governo, indústria, jurídico, serviços, turismo e saúde, e atende clientes em âmbito nacional.

A unidade da empresa selecionada para esta pesquisa atua especificamente no segmento de saúde, sendo que os sistemas desenvolvidos pela empresa dão suporte à gestão de milhares de usuários de planos de saúde no território nacional.

Está localizada em um município paranaense e conta com aproximadamente trezentos colaboradores. Sua estrutura laborativa divide os colaboradores em times, sendo cada um deles responsável por atender demandas específicas em desenvolvimento, testes de qualidade, correção e atendimento de suporte. De acordo com o Gerente de Recursos Humanos, a empresa incentiva e estimula o questionamento e a troca de informações entre colaboradores, o que, segundo ele, aprimora o ambiente de trabalho e estreita as relações.

\section{O Compartilhamento do Conhecimento no Programa Mentor}

A unidade em estudo iniciou o seu Programa Mentor em 2016, o qual estava em vigor até o momento da pesquisa. Tal Programa possui regulamento criado pela própria organização, com código interno que o normatiza e identifica. O objetivo principal do Programa é o de estimular o compartilhamento de conhecimento dos especialistas por meio da criação de Núcleos de Formação Acelerada. É escolhido um profissional nível sênior, o qual assume a responsabilidade pela gestão de um determinado núcleo, composto por quatro colaboradores, durante um período de doze meses. A missão do mentor é facilitar a aprendizagem dos mentorados, acompanhando sua evolução e participação na carreira. Com a implementação do Programa, a expectativa da unidade é a formação acelerada dos desenvolvedores de sistema de níveis júnior e pleno, potencializando a força de trabalho das equipes, bem como a qualidade dos produtos e serviços que entrega.

$\mathrm{Na}$ fase inicial do processo de compartilhamento do conhecimento, iniciação, as ações estão voltadas para a análise de necessidades de conhecimento, exploração de oportunidades para emprego de novos conhecimentos e identificação das fontes de conhecimento (Tonet \& Paz, 2006).

Nesse sentido, na empresa objeto de estudo a análise das necessidades de conhecimento impulsiona o Programa Mentor, sendo que o próprio desenvolvimento do trabalho indica as necessidades de conhecimento dos times. Uma vez que a equipe identifica a carência de um conhecimento exigido para o desenvolvimento, essa necessidade é apresentada ao gestor de produto, que mobiliza suas ações para incluir esse saber como uma necessidade de conhecimento a ser compartilhado no Programa.

É também nessa fase que ocorre a seleção das fontes de conhecimento, ou seja, do mentor. Sob a ótica do Gerente de Recursos Humanos, os possíveis mentores são identificados a partir dos critérios de conhecimento avançado, boa comunicação e didática para o ensino. Uma vez identificados, é feito então um convite para participação no Programa. Essa prática é defendida por Minello, Ferreira, Yonamine e Scherer (2011), os quais consideram que a seleção deve ser baseada no critério de experiência, sendo que o mentor deve ser um colaborador e ter posição de destaque dentro da empresa, bem como atuar como multiplicador e oferecer orientações ao mentorado.

Dentre os motivos que levam os mentores a atuarem no Programa Mentor e a compartilhar aquilo que sabem, os dados da pesquisa mostraram que o compartilhamento do conhecimento ocorre por meio da prática de ensino, da discussão de assuntos de mútuos interesses e da troca de experiências, além da aprendizagem com os mentorados. Reis (2016) considera que a motivação do colaborador detentor do conhecimento é o ponto de partida para a aprendizagem. Do mesmo modo como identificaram Marcolino, Lourenço e Reali (2016), nesta pesquisa a troca de experiências entre experientes e iniciantes representou um espaço de aprendizado profissional prático.

Quanto à seleção dos mentorados, o Gerente de Recursos Humanos informou que quando o corpo de mentores está definido, a unidade cria as turmas e abre inscrições para os interessados, os quais se inscrevem considerando os Núcleos aos quais 
pertencem, o que possibilita a escolha de qual time de mentoria têm interesse em participar durante o Programa Mentor.

O processo seletivo para ingresso no Programa considera, além da avaliação de desempenho, entrevistas individuais para averiguar as expectativas e o nível de interesse dos colaboradores. Assim, no momento inicial do Programa as expectativas dos mentorados são colhidas; é aplicada uma entrevista inicial, a partir da qual se constrói um contrato de expectativas entre mentor, mentorado e liderança. Os mentorados, quando questionados sobre as expectativas que os levaram a querer participar do Programa Mentor, mencionaram que, além de adquirir conhecimentos em diversas esferas, buscam também serem pessoas de referência dentro da unidade.

Durante o levantamento de expectativas também são estabelecidas as metas a serem atingidas. Sobre esse quesito o Gerente de Recursos Humanos afirmou que "são definidas metas com base nos pontos que serão desenvolvidos no decorrer do Programa. Elas são estabelecidas entre mentor e mentorado". Sob a ótica dos mentorados, 90\% deles também afirmaram que o estabelecimento de metas ocorre no início do Programa. Tais afirmações são encontradas nas palavras dos mentorados: "Através da apresentação da proposta do programa, acompanhamento do cumprimento de objetivos individuais para cada participante do programa, além de feedbacks informais".

Em relação aos atributos de conhecimento compartilhado, houve praticamente unanimidade entre os mentorados em definir seus mentores: todos apresentam características como boas técnicas comunicativas, prestígio na organização, domínio do conhecimento compartilhado e competência em relação às funções que desempenham na empresa. Esses dados estão em conformidade com Tonet e Paz (2006), que afirmam que o nível de domínio do conhecimento é fundamental, pois ninguém é capaz de repassar algo que não possui; por sua vez, se a fonte for muito especializada poderá ter dificuldade para sintonizar-se com um destinatário iniciante ou pouco experiente. No entanto, salientam Souza et al. (2010) que o compartilhamento depende de reciprocidade e de confiança.

De forma complementar, os mentores também citaram os atributos de seus respectivos mentorados relacionados à comunicação. Ao serem questionados se os mentorados se comunicam facilmente, $75 \%$ responderam afirmativamente. Além disso, $100 \%$ dos mentores afirmaram que os mentorados sabem ouvir e refletir sobre os conhecimentos recebidos, além de conhecimentos sobre como elaborar perguntas para esclarecer informações recebidas e direcionar a sua aplicabilidade.

$\mathrm{Na}$ segunda fase do compartilhamento de conhecimento, implementação, as ações estão voltadas para a integração de fontes (mentores) e destinatários do conhecimento (mentorados). De acordo com os mentores, os conhecimentos transmitidos entre suas equipes vão além daqueles que se restringem ao desenvolvimento e ao negócio. Para atingir objetivos tão diversos, verificou-se que os mentores empregam diferentes processos e ações na transmissão do conhecimento. Na Tabela 6 apresentam-se os formatos nos quais o mentor compartilha seus conhecimentos com os mentorados.

Os mentores compartilham seus conhecimentos por meio de recursos específicos, tais como pair programming (programação em pares de programadores, que revezam entre si o desenvolvimento de determinados códigos), fomento à leitura e à discussão de assuntos em grupo, apresentações regulares (reuniões parecidas com seminários), colaboração mútua e constante nas atividades diárias, revisão da análise e do código, reuniões semanais, acompanhamento, e-mails, chats e reuniões informais. Além dessas ações e recursos para compartilhar conhecimento, os mentorados apontaram ainda o valor didático das situações vivenciadas na unidade durante o Programa, consideradas como importantes para seu desenvolvimento. Essa visão demonstra a
Tabela 6

Formas de compartilhamento de conbecimentos entre mentor e mentorado

Formas de

Compartilhamento

de Conhecimento

\begin{tabular}{ll}
\hline & - Reuniões \\
& - Desenvolvimento em conjunto de novos códigos \\
Presencial & - Disponibilidade para esclarecimento de dúvidas \\
& - Utilizrogrãão de exemplos práticos \\
& - Avaliação formal e informal \\
& - Tarefas de casa \\
À distância & - Indicações de leitura \\
& - Indicação de cursos complementares \\
& Lista de atividades para as semanas seguintes
\end{tabular}

Nota. Fonte: Elaborado pelos autores

importância das influências naturais do processo que, na visão dos mentorados, incluem a absorção do conhecimento, a visibilidade que o Programa tem dentro da unidade e os projetos que eventualmente foram encabeçados pelos mentorados, o que fortalece o senso de pertencimento e responsabilidade entre os participantes. Esses resultados corroboram com Ayres e Popadiuk (2016), que também constataram a melhoria da capacidade de absorção no compartilhamento de conhecimento em projetos de software.

No que diz respeito à aproximação das relações mentor-mentorado, todos os mentores informaram que ficaram mais próximos de seus mentorados durante a execução do Programa Mentor. Segundo um mentor, "o compartilhamento de experiências e histórias trouxe mais cumplicidade na relação. Encontros fora do trabalho se tornaram rotineiros e as relações evoluíram na maioria dos casos para o nível de amizade". Para os mentorados a percepção é a mesma, ou seja, aproximaram-se mais de seus mentores durante a execução do Programa. Esses resultados indicam que o mentor do caso em estudo atuou, de fato, como modelo e ofereceu suporte psicossocial ao grupo, corroborando com os resultados encontrados por Oliveira Neto e Souza-Silva (2017).

$\mathrm{Na}$ terceira fase do processo de compartilhamento do conhecimento, apoio, as ações estão voltadas para a comprovação, assimilação e exercício do conhecimento recebido. No que concerne à utilização do conhecimento recebido no cotidiano, todos os mentores afirmaram que os mentorados assimilaram os conhecimentos necessários. Na percepção de um mentor, embora tenha ocorrido interrupção durante o Programa, por motivos de reorganização da estrutura hierárquica da unidade, seus mentorados evoluíram: "Na minha equipe houve uma disruptura na continuidade do programa, então acredito que o tempo acabou sendo insuficiente. Mesmo assim foi perceptível a evolução de todos, principalmente daqueles que considerávamos com maior potencial".

$\mathrm{Na}$ perspectiva dos mentorados, a pesquisa revelou também as maneiras pelas quais os novos conhecimentos adquiridos durante o Programa Mentor são utilizados na execução das atividades diárias. As relações estabelecidas nos resultados indicam aplicação de técnicas e regras de negócio aprendidas; melhor capacidade de análise voltada para soluções; melhoria no desenvolvimento de códigos; aplicação dos conhecimentos aprendidos em novas habilidades e análises; e compartilhamento dos conhecimentos aprendidos com a equipe.

Ao serem questionados sobre as habilidades adquiridas ao

término do Programa Mentor, os mentorados destacaram novas possibilidades em seu repertório profissional. Na Tabela 7 são sistematizadas as percepções dos mentorados acerca das novas habilidades adquiridas com a conclusão do Programa Mentor.

O Programa Mentor ocorre mediante planejamento feito em sua estruturação. Consequentemente, mentores e mentorados são constantemente avaliados pela liderança quanto à assi milação e à utilização do conhecimento recebido ao término 
Tabela 7

Novas habilidades adquiridas pelos mentorados

\begin{tabular}{cc}
\hline Mentorado & Habilidades \\
\hline & "Melhora em técnicas de programação, buscando sempre \\
programar com boas práticas e aplicar, na medida do possível, \\
devido ao sistema legado, novas maneiras de programar, evitan- \\
do problemas antigos de códigos duplicados e baixa manute- \\
nibilidade de processo. Na área de negócio, habilitou a criar \\
análises mais profundas para que uma solicitação de alteração \\
não gerasse tantos impactos inesperados no sistema."
\end{tabular}

D "Aumentou meu conhecimento técnico na área de programação e aprendi novas regras de negócio."

\begin{tabular}{|c|c|}
\hline $\mathrm{E}$ & $\begin{array}{l}\text { "Maior senso crítico com relação às novas implementações, } \\
\text { quanto à real necessidade destas e quanto à solução proposta } \\
\text { pelo cliente." }\end{array}$ \\
\hline $\mathrm{F}$ & $\begin{array}{l}\text { "Agora, consigo ter uma visão macro do sistema. Consigo en- } \\
\text { tender e opinar sobre arquiteturas do sistema da mesma forma } \\
\text { que o mentor. Debatemos para encontrar melhores soluções." }\end{array}$ \\
\hline G & $\begin{array}{l}\text { "Melhor entendimento sobre as regras do negócio emalgumas } \\
\text { funcionalidades do sistema." }\end{array}$ \\
\hline $\mathrm{H}$ & $\begin{array}{l}\text { "Melhor capacidade de planejamento e execução das tarefas, } \\
\text { que refletiu em mais organização. Maior conhecimento sobre as } \\
\text { regras do negócio, que refletiu em maior agilidade na identifica- } \\
\text { ção/resolução de problemas." }\end{array}$ \\
\hline I & $\begin{array}{c}\text { "Melhora na escrita e na qualidade do código, na comunicação } \\
\text { com clientes e na análise de sistemas." }\end{array}$ \\
\hline $\mathrm{J}$ & $\begin{array}{c}\text { "Melhora na capacidade de análise de negócio e dos impactos } \\
\text { que podem ser causados por uma alteração a ser realizada no } \\
\text { sistema." }\end{array}$ \\
\hline
\end{tabular}

Nota. Fonte: Elaborado pelos autores .

do programa. Os mentores são avaliados a partir dos instrumentos de avaliação de desempenho técnico e comportamental, havendo ainda uma autoavaliação, na qual se compara a visão que o mentor tem de si e de sua conduta em relação à visão de seu líder. Segundo o gestor do programa, "o mentor passa pela avaliação de desempenho com questões técnicas e comportamentais". No que tange aos mentorados, ele afirma que "são avaliados pelo líder e mentor, além de fazerem sua autoavaliação, para, então, no feedback, alinhar como se veem e como seus líderes o fazem”.

Por sua vez, a totalidade dos mentores ratificou a afirmação do gerente de RH em relação às avaliações, que ocorrem de modo específico. Segundo um dos mentores, a avaliação "ocorre no dia a dia com as atividades que realizam, avaliando o grau de dependência e de qualidade do trabalho executado". Já outro mentor declarou que essa prática se dá "no próprio processo de avaliação de desempenho, olhando as metas estabelecidas e seu cumprimento".

Por fim, todos os mentores afirmaram que não há descontinuidade de relacionamento entre mentor e mentorado após o término do programa. Essa perspectiva de desenvolvimento comportamental é compartilhada por Poncioni (2014), o qual considera que o mentor, quanto aos seus valores, comportamentos e atitudes, apresenta-se como um modelo a ser seguido, e o mentorado identifica-se com ele. A partir dessa identificação, o mentorado passa a admirar, respeitar e imitar o seu mentor.

$\mathrm{Na}$ última fase do processo de compartilhamento de conhecimento (incorporação), as ações estão voltadas para a disseminação e a aplicação do conhecimento compartilhado. $\mathrm{Na}$ disseminação do conhecimento, para um dos mentorados é possível identificar as nuances possibilitadas pelo Programa Mentor: "a quebra de gelo entre os mais novos com relação aos mais velhos da empresa ajuda na disseminação do conhecimento”. Tal afirmação está embasada não apenas na relação mentor-mentorado, mas também na "gradativa troca de conhecimentos", conforme comentou outro mentorado.

Quanto aos estímulos, embora 25\% dos mentores tenham ressaltado o patrocínio da unidade para a participação em congressos e eventos, $75 \%$ sinalizaram a falta de estímulo por parte da empresa no estreitamento de vínculos. Os mesmos resultados se repetem na visão dos mentorados, pois a pesquisa revelou que, para $90 \%$ deles, a empresa não tomou medidas para fortalecer os laços entre estes e os mentores. É importante salientar que durante a realização do programa os mentores recebem uma bonificação mensal em seus salários e os mentorados, quando atingem os objetivos estabelecidos no início do programa, têm possibilidades de promoção. Contudo, faz-se necessário que a empresa procure mecanismos que permitam fortalecer os laços entre mentores e mentorados a fim de propiciar continuamente o compartilhamento de conhecimentos e a aprendizagem, o que depende também da cultura organizacional (Oliveira Neto \& Souza-Silva, 2017).

Segundo a visão dos mentores, entre as formas que a empresa utiliza para reconhecer as capacidades dos mentorados estão a atribuição de responsabilidades, as promoções de cargo, os aumentos de salários, os feedbacks e a maior autonomia e reconhecimento formal perante o grupo. Essa estrutura de reconhecimento e recompensa é importante, pois fomenta o interesse para que ocorram novas turmas do programa, segundo o gerente de RH.

Ao serem questionados acerca das ações tomadas pela empresa para reconhecer as capacidades do mentorado, 50\% afirmaram que não houve nenhum tipo de reconhecimento por parte da organização em relação às suas capacidades; outros 50\% relataram, respectivamente, sobre as formas de reconhecimento: "Proporciona atividades onde a responsabilidade é maior, possibilitando que o mentorado seja provado tanto tecnicamente quanto em termos de negócio"; "feedbacks"; "poucas, o programa em si foi uma experiência fantástica. Aprendi muito e isso com certeza entrará para meu currículo, mas a empresa não valorizou como deveria"; "delegar tarefas que exijam maior responsabilidade e domínio técnico e de negócio"; e "análise comportamental e evolução técnica".

Por fim, em relação à continuidade do relacionamento entre mentores e mentorados e se estes contam com o auxílio de seus respectivos mentores após o término do Programa Mentor, os dados mostraram que 20\% dos mentorados deixaram a empresa nesse período e, portanto, não tiveram mais apoio de seus mentores. Outros $80 \%$ afirmaram que a relação continuou e, para alguns, esse relacionamento estreitou-se. Nas palavras de um dos mentorados, "a relação que tenho com meu mentor é mais aberta agora do que no início do programa. Hoje, não tenho mais medo dele. Quando tenho algum problema me sinto mais à vontade para pedir ajuda".

Uma das influências observadas do Programa Mentor em relação ao processo de compartilhamento de conhecimento está ligada ao tempo que os mentorados levam para aplicar o conhecimento recebido. Nesse sentido, os resultados da pesquisa demonstraram que 50\% dos mentores consideram seus mentorados aptos a aplicar o conhecimento aprendido no período de um a dois meses após a aprendizagem; 25\% dos mentores afirmaram serem necessários de dois a quatro meses; e os outros $25 \%$ mencionaram de quatro a seis meses. Por sua vez, na visão dos mentorados, 60\% indicaram a necessidade de menos de um mês para aplicar os novos conhecimentos adquiridos, ao passo que $20 \%$ informaram de um a dois meses; $10 \%$ indicaram de dois a quatro meses e, por fim, outros 10\% mencionaram serem necessários de quatro a seis meses para aplicarem o conhecimento adquirido.

Os mentores descreveram as principais mudanças observadas nos mentorados após o compartilhamento de co- 
nhecimentos no Programa Mentor: os participantes apresentam mais responsabilidade, mais iniciativa, busca por aprendizagem contínua, posicionamento mais adequado frente ao cliente, formas mais adequadas de expressão e comunicação, confiança voltada para o trabalho, voz ativa dentro da empresa e posição de profissional referenciado na organização.

Quanto às influências que o Programa Mentor teve sobre os mentorados quando questionados se aprenderam a ouvir e a refletir sobre o conhecimento recebido, 100\% dos mentorados responderam positivamente. $\mathrm{Na}$ Tabela 8 apresentam-se as principais avaliações dos mentorados acerca dos benefícios proporcionados pelo programa.

Os resultados mostram, ainda, que ocorreu o aprimoramento da comunicação formal e a integração entre pessoas no trabalho, importante para o compartilhamento de conhecimento. O estudo de Joseph e Jacob (2011) corrobora esse aspecto, confirmando a importância da prática de mentoring, o que indica a relevância da criação de um programa formal, pois facilita o compartilhamento de conhecimento, principalmente dos

Tabela 8

Benefícios proporcionados pelo Programa Mentor

\begin{tabular}{cc} 
Mentorado & Benefícios \\
\hline A & $\begin{array}{c}\text { "O programa gerou uma melhora em alguns pontos deficientes } \\
\text { tecnicamente, possibilitando que eu crescesse como profissional, } \\
\text { ajudando a me tornar um referencial técnico e de negócio na } \\
\text { equipe em que atuo." }\end{array}$ \\
\hline B & "Adquirir conhecimentos de forma acelerada trazendo novos \\
desafios para a carreira."
\end{tabular}

D "Melhoria na técnica e maior senso crítico com relação às atividades desenvolvidas."

\begin{tabular}{cc}
\hline E & $\begin{array}{c}\text { "Me incentivou a continuar estudando para aprender mais e } \\
\text { aperfeiçoando o que já conheço na área de desenvolvimento de } \\
\text { software." }\end{array}$ \\
\hline F & $\begin{array}{r}\text { "Maior aproximação em relação ao mentor, facilitando a obten- } \\
\text { ção de informações gerais e o interesse deste em ajudar." }\end{array}$ \\
\hline G & $\begin{array}{c}\text { "Com a troca de informações, também acabei me interessando } \\
\text { por assuntos atuais que não necessariamente estão diretamente } \\
\text { ligados à empresa." }\end{array}$ \\
\hline H & "Melhorou minha comunicação, meu conhecimento de negócio \\
e minha organização e planejamento."
\end{tabular}

profissionais menos experientes, para que estes não se sintam distanciados da comunidade de conhecimento estabelecida.

Ainda segundo os resultados da pesquisa, existem aspectos que carecem de melhorias no Programa Mentor, como a adoção de medidas que propiciem o fortalecimento das relações entre mentores e mentorados após o término do programa, o reconhecimento dos esforços dispensados por mentores e mentorados e o incremento na aplicação de TIs como recurso para maximizar o compartilhamento de informações e conhecimentos. Tal afirmação é defendida por Gonzalez e Melo (2018) ao declararem que os sistemas de TI são facilitadores do processo de gestão do conhecimento, cabendo aos indivíduos a ação propriamente dita, a fim de que esse conhecimento armazenado e distribuído retorne em forma de valor para a organização.

A partir da similaridade entre as fases do compartilhamento de conhecimento e do mentoring e dos dados coletados nas entrevistas, foram identificados os elementos relativos ao processo de compartilhamento de conhecimento e as ações da prática do mentoring que contribuem para que esse processo ocorra. Dessa forma, na fase de iniciação ocorre a identificação de necessidades e de fontes de conhecimento. Em contrapartida, como ações pautadas na prática do mentoring encontram-se a seleção de mentores e mentorados, suas respectivas expectativas e o estabelecimento de metas. $\mathrm{Na}$ fase de implementação ocorre a integração de fontes e destinatários de conhecimento. As ações da prática do mentoring identificadas estão voltadas para o compartilhamento e o recebimento do conhecimento, para a aproximação dos atores e para as situações presenciadas durante a execução do programa. A fase de apoio é orientada ao exercício do conhecimento e, desse modo, são empregadas ações de utilização e avaliação do conhecimento recebido pelos mentorados. Por fim, na fase de incorporação ocorre a disseminação do conhecimento compartilhado e, em observância às ações do mentoring, destacam-se o fortalecimento da relação mentor-mentorado e o reconhecimento de suas respectivas capacidades.

No caso em estudo, o Programa Mentor representa um ambiente de efetivo compartilhamento de conhecimento e de aprendizagem coletiva (Oliveira Neto \& Souza-Silva, 2017; K. F. F. Silva, 2008). A transmissão de conhecimentos é favorecida por um ambiente de proximidade das relações, como mencionaram os participantes da pesquisa. Também para alguns integrantes da pesquisa, a empresa valoriza o aprendizado oriundo da atuação no programa e, para outros, isso não ocorre. No entanto, de modo geral, os participantes relataram que mudaram suas práticas e passaram a ter maior domínio do trabalho realizado, contribuindo para se situarem melhor nas atividades que realizam. É importante salientar que 20\% dos participantes deixaram a empresa, de forma que a rotatividade de pessoal limitou a extensão dos resultados a todos os integrantes da pesquisa.

\section{Conclusões e Sugestões para Pesquisas Futuras}

O objetivo desta pesquisa foi descrever a relação entre práticas de mentoring e o processo de compartilhamento de conhecimento em uma empresa de desenvolvimento de software. De acordo com os dados da pesquisa, o mentoring é uma prática que propicia o compartilhamento de saberes e o aprimoramento de experiências, capacitando os participantes para o trabalho, além de contribuir para a melhoria nos relacionamentos com colegas e clientes.

Os resultados do estudo evidenciaram a importância de aspectos técnicos e comportamentais no Programa Mentor, os quais favoreceram o processo cognitivo almejado com a implementação do programa.

Como limitação da pesquisa destaca-se que os resultados encontrados são válidos para a empresa estudada, não podendo ser generalizados. Além disso, o corte transversal da investigação representa também uma restrição na medida em que análises longitudinais podem trazer novos elementos.

Como contribuição teórica, a pesquisa mostrou os resultados da implementação de um programa de mentoring em um contexto específico, o de empresas de tecnologia. Os resultados podem estimular outras organizações do setor a implementarem programas de mentoring e fomentarem a disseminação dessa prática.

Para futuras pesquisas sugere-se o estudo de outras práticas de compartilhamento de conhecimento em empresas de desenvolvimento de software, as quais podem evidenciar de maneira mais adequada o processo de compartilhamento de conhecimento nessas organizações. Além disso, outros estudos futuros explorar a relação entre mentorado, aprendizagem e lançamento de novos produtos ou serviços em empresas de software. 


\section{Referências}

Agarwal, N. K., \& Islam, M. A. (2015). Knowledge retention and transfer: How libraries manage employees leaving and joining. Vine, 45(2), 150-171. https://doi.org/10.1108/VINE-06-2014-0042

Almeida, N. C. P., \& Souza-Silva, J. C. (2015). Aprendizagem organizacional e formação de gestores: como aprendem os gestores em uma indústria do setor petroquímico. Revista de Gestão, São Paulo, 22(3), 383-404. Recuperado de https://www.sciencedirect.com/science/article/pii/ S180922761630128X

Anand, A., \& Walsh, I. (2016). Should knowledge be shared generously? Tracing insights from past to present and describing a model. Journal of Knowledge Management, 20(4), 713-730. https://doi.org/10.1108/JKM-10-2015-0401

Ayres, R. S. M., \& Popadiuk, S. (2016). Transferência de conhecimento, Aprendizagem e desenvolvimento de capacitações organizacionais em projetos interorganizacionais de software. Organização \& Sociedade, 23(79), 1-18. https://doi.org/10.1590/1984-9230792

Bellodi, P. L., \& Martins, M. A. (2005). Tutoria-mentoring na formação médica. São Paulo: Casa do Psicólogo.

Berlo, D. K. (1970). O processo da comunicação: introdução à teoria e prática. Rio de Janeiro: Editora Fundo de Cultura S.A.

Bertalanffy, L. V. (1975). Teoria geral de sistemas. Petropólis: Vozes.

Binotto, E., Nakayama, M. K., \& Siqueira, E. S. (2013). A criação de conhecimento para a gestão de propriedades rurais no Brasil e na Austrália. RESR, 51(4), 681-698. https://doi.org/10.1590/S0103-20032013000400004

Brachos, D., Kostopoulos, K., Soderquist, K. E., \& Prastacos, G. (2007). Knowledge effectiveness, social context and innovation. Journal of Knowledge Management, 11(5), 31-44. https://doi.org/10.1108/13673270710819780

Cooper, D. R., \& Schindler, P. S. (2003). Métodos de pesquisa em Administração. Porto Alegre: Bookman.

Dalkir, K. (2011). Knowledge Management in Theory and Practice. Burlington: Elsevier.

Gonzalez, R. V. D., \& Martins, M. F. (2017). O processo de gestão do conhecimento: uma pesquisa teórico-conceitual. Gestão \& Produção, 24(2), 248-265. https://doi.org/10.1590/0104-530X0893-15

Gonzalez, R. V. D., \& Melo, T. M. (2018). Inovação por exploração e explotação do conhecimento: um estudo empírico do setor automobilístico. Gestão \& Produção, 25(1), 1-15. https://doi.org/10.1590/0104-530X3899-17

Joseph, B., \& Jacob, M. (2011, March). Knowledge Sharing Intentions among IT Professionals in India. Em International Conference on Information Intelligence, Systems, Technology and Management (pp. 23-31). Springer, Berlin, Heidelberg. Recuperado de https://link.springer.com/ chapter/10.1007/978-3-642-19423-8 3

Kim, S., \& Lee, H. (2006). The impact of organizational context and information technology on employee knowledge-sharing capabilities. Public Administration Review, 66(3), 370-385. https://doi.org/10.1111/j.1540-6210.2006.00595.x

Kram, K. E. (1988). Mentoring at work: developmental relationships in organizational life. Boston: University Press of America. Recuperado de https://psycnet.apa. org/record/1988-97625-000

Kuo, T. H. (2013). How expected benefit and trust influence knowledge sharing. Industrial Management \& Data Systems, 113(4), 506-522. https://doi. org/10.1108/02635571311322766

Marcolino, T. Q., Lourenço, G. F., \& Reali, A. M. M. R. Q. (2016). “Isso eu levo para a vida": aprendizagem da prática profissional em uma comunidade de prática. Interface - Comunicação, Saúde, Educação, 21(61), 1-11. https://doi. org/10.1590/1807-57622016.0099

Massingham, P. (2014). An evaluation of knowledge management tools: Part 1 - managing knowledge resources. Journal of Knowledge Management, 18(6), 1075-1100. https://doi.org/10.1108/JKM-11-2013-0449

Miguel, L. A. P., \& Popadiuk, S. (2019). The semiotics of tacit knowledge sharing: a study from the perspective of symbolic interacionism. Cadernos EBAPE, 17(3), 1-14. https://doi.org/10.1590/1679-395172519x

Minello, I., Ferreira, M. A., Yonamine, R., \& Scherer, I. B. (2011). A prática do Mentoring com jovens engenheiros: um estudo exploratório. Revista de administração da UFMS, 4(2), 233-250. Recuperado de https://www.redalyc. org/pdf/2734/273419420004.pdf

Moreno Junior, V.A., Cavazotte, F. S. C. N, \& Arruda, R. R. (2014). Conhecimento compartilhado, recursos de TI e desempenho de processos de negócios. Revista de Administração de Empresas, 54(2), 1-17. https://doi. org/10.1590/S0034-759020140205

Oliveira Neto, C. C. O., \& Souza-Silva, J. C. (2017). Aprendizagem, mentoria e cultura organizacional de aprendizagem: $O$ estudo de caso da Performance Consultoria e Auditoria. Revista Eletrônica de Administração (Porto Alegre), 23(spe), 60-92. https://doi.org/10.1590/1413-2311.168.62959

Osinski, M., Roman, D. J., \& Selig, P. M. (2015). Compartilhamento de Conhecimento: Estudo Bibliométrico das Publicações acadêmicas realizadas de 1994 a 2014. Perspectivas em Ciência da Informação, 20(4), 149-162. https:// doi.org/10.1590/1981-5344/2512
Poncioni, L. A. C. (2014). Relações de mentoria de gerentes de projetos e membros de equipes de projetos. (Dissertação de Mestrado). Faculdade Boa Viagem, Recife, PB, Brasil. Recuperado de http://imagens.devrybrasil.edu.br/wp-content/ uploads/sites/88/2015/09/08130055/LUCIANA-ALVES-CAMPELOPONCIONI.pdf

Reis, I. W. (2016). O Papel do Compartilhamento do Conbecimento a partir da Gestão do Conhecimento (Dissertação de Mestrado, Escola de Engenharia de São Carlos, Universidade de São Paulo, São Carlos, SP, Brasil). Recuperado de http:// www.teses.usp.br/teses/disponiveis/18/18157/tde-05102016-135303/ en.php

Rodriguez, I. A., Muniz, J., \& Munyon, T. (2018). A relação entre clima organizacional e gestão do conhecimento: Uma revisão da literatura. Revista Psicologia: Organizacõos e Trabalho, 18(1), 316-325. https://doi.org/10.17652/ rpot/2018.1.13244

Santos, B. A. (2015). Coaching e mentoring como práticas de compartilhamento do conhecimento: estudos de casos em empresas públicas paulistas. (Dissertação de Mestrado, Universidade Metodista de São Paulo, São Bernardo do Campo, SP, Brasil). Recuperado de http://tede.metodista.br/jspui/handle/ tede/1473

Silva, C. R. E. (2010). Orientação Profissional, mentoring, coaching e counseling: algumas singularidades e similaridades em práticas. Revista Brasileira de Orientação Profissional, 11(2), 299-309. Recuperado de https://www.redalyc. org/pdf/2030/203016849014.pdf

Silva, K. F. F. (2008). A prática da mentoria no desenvolvimento de pessoas nas organizacõoes. (Dissertação de Mestrado, Escola Brasileira de Administração Pública e de Empresas, Fundação Getúlio Vargas, São Paulo, SP, Brasil). Recuperado de https://bibliotecadigital.fgv.br/dspace/bitstream/handle/10438/3366/ ACF2BB.pdf? sequence $=1$ \&is Allowed $=\mathrm{y}$

Smite, D., Moe, N. B., Sablis, A., \& Wohlin, C. (2017). Software teams and their knowledge networks in large-scale software development. Information and Software Technology, 86, 71-86. https://doi.org/10.1016/j.infsof.2017.01.003

Souza, Y. L., Vasconcelos, M. C. R. L., Judice, V. M. M., \& Jamil, G. L. (2010). A contribuição do compartilhamento do conhecimento para o gerenciamento de riscos em projetos: um estudo na indústria de software. JISTEM - Journal of Information Systems and Technology Management, 7(1), 183-204. https://doi. org/10.4301/S1807-17752010000100008

Thayer, L. O. (1979). Comunicação fundamentos e sistemas: na organização, na administração, nas relações interpessoais. São Paulo: Atlas.

Thompson, J. J. (1973). Anatomia da comunicação. Rio de Janeiro: Bloch Editores S.A.

Tonet, H. C., \& Paz, M. G. T. (2006). Um Modelo para o Compartilhamento de Conhecimento no Trabalho. Revista de Administração Contemporânea $\mathrm{R} A C$, 10(2), 75-94. https://doi.org/10.1590/S1415-65552006000200005

Van den Hooff, B., \& Van Weenen, F. de L. (2004). Committed to share: commitment and $\mathrm{CMC}$ use as antecedents of knowledge sharing. Knowledge and Process Management, 11(1), 13-24. https://doi.org/10.1002/kpm.187

Yang, Y. (2007). A Framework for Decision Support Systems Adapted to Uncertain Knowledge. (Tese de Doutorado, Karlsruhe Institute of Technology, Karlsruhe, Alemanha). Recuperado de https://pdfs.semanticscholar. org/783f/c1d99b5fe5754c0e925932ea3ee44c108d02.pdf

Yin, R. K. (2005). Estudo de caso. Porto Alegre: Bookman.

Young, R. (2010). Knowledge management tools and techniques manual. Tokyo: Asian Productivity Organization. Recuperado de https://www.apo-tokyo.org/ publications/wp-content/uploads/sites/5/ind-43-km tt-2010.pdf

Zachary, L. J. (2011). The Mentor's Guide: Facilitating Effective Learning Relationships. John Wiley \& Sons. 